\title{
"UM CAMPO DE REFUGIADOS SEM CERCAS": ETNOGRAFIA DE UM APARATO DE GOVERNO DE POPULACÕES REFUGIADAS
}

\author{
Vanessa Perin \\ Fundação Casa de Rui Barbosa - Brasil
}

Resumo: Através do trabalho etnográfico realizado em um dos programas assistenciais da Cáritas Arquidiocesana de São Paulo, o Centro de Acolhida para Refugiados (CAR), o presente artigo procura descrever a malha de relações estabelecidas pelo aparato de governo das populações refugiadas no Brasil. Conectado a organizações como o Alto Comissariado das Nações Unidas para Refugiados, o Comitê Nacional para Refugiados, dentre outras organizações, o trabalho do CAR é parte de um dispositivo institucional mais amplo, que envolve, além da assistência humanitária, ações simultâneas de administração e controle que perpassam essa população. Procuro, assim, compreender como tal aparato coloca em operação um mecanismo de governo - aqui denominado olho do Estado - e como este produz um sujeito que lhe seja apreensível, a partir da análise das relações estabelecidas entre os refugiados e as diversas organizações com as quais entram em contato ao solicitarem refúgio: $o$ "campo de refugiados sem cercas".

Palavras-chave: aparato de governo, Estado, organizações, refúgio.

Abstract: Through an ethnographic study conducted in one of the assistance programs of Cáritas Arquidiocesana de São Paulo, the Centro de Acolhida para Refugiados (CAR), this article aims to describe the network of relations established by the government apparatus of refugee populations in Brazil. Connected to organizations such as the United Nations High Commissioner for Refugees, the National Committee for Refugees and among other organizations, the work of CAR is part of a broader institutional device, which involves beyond humanitarian assistance, simultaneous actions of management and control pervade this population. Thus, I tried to understand how this apparatus puts into operation a mechanism of government - here called eye of the state - and how this produces a subject that will be understandable, from the analysis of the relationships established between the refugees and the various organizations they contact to request refuge: the "refugee camp without fences".

Keywords: government apparatus, organizations, refuge, state. 


\section{Introducão}

Este artigo baseia-se em uma pesquisa ${ }^{1}$ mais ampla, que consistiu de modo geral em um estudo de singularidades do caso brasileiro de acolhida e assistência a grupos refugiados. Em tal pesquisa procurei etnografar a dinâmica dos atendimentos prestados a essa população, realizados por um dos programas desenvolvidos pela Cáritas Arquidiocesana de São Paulo (Casp): ${ }^{2}$ o Centro de Acolhida para Refugiados (CAR).

Nesse sentido, mais do que partir da categoria estanque e fixa de refugiado definida pela normativa jurídica, ${ }^{3}$ através da etnografia busquei chegar às múltiplas relações de poder que iam constituindo esses sujeitos enquanto tais, produzindo-os como um grupo-alvo de determinados saberes e que deveria, portanto, receber um cuidado e uma intervenção particular, ou como uma população que precisaria ser gerida ${ }^{4}$ por um aparato institucional.

Reconhecido por seus próprios funcionários como um "centro de referência”, o CAR está organizado enquanto um escritório. Atuando como uma etapa de triagem dos casos que acessam o aparato institucional responsável por lidar com a população refugiada que chega ao Brasil, este formado pelo Alto Comissariado das Nações Unidas para Refugiados (Acnur), o Comitê Nacional para Refugiados (Conare) e por um grande número de organizações estatais e não governamentais, tal programa de assistência pôde se apresentar

\footnotetext{
Pesquisa financiada pela Fapesp.

2 Organização não governamental (ONG) católica ligada à rede Caritas Internationalis, que desenvolve e financia projetos de ajuda humanitária e de desenvolvimento social em todo o mundo. A Casp é atualmente um dos principais organismos responsáveis pelo trabalho de recepção, assistência e integração dos refugiados e solicitantes de refúgio que chegam ao Brasil.

3 Um refugiado é caracterizado como aquela pessoa que tem de sair de seu país de origem em razão de um fundado temor por sua vida, segurança ou liberdade, uma vez que tal país não quer ou não pode mais oferecer-lhe proteção (Moreira, 2006). Conforme a Convenção de 1951 sobre o Estatuto dos Refugiados da Organização das Nações Unidas (ONU) as causas reconhecidas para a solicitação de refúgio são baseadas em um fundado temor de perseguição por raça, etnia, religião, grupo social ou político. A legislação brasileira também reconhece como refugiado aquela pessoa que devido a contextos de grave e generalizada violação de direitos humanos teve de deixar seu país de nacionalidade.

4 Partindo de uma perspectiva foucaultiana, compreendo gestão como uma nova forma de intervenção estatal que vai fazer com que regulamentações necessárias e encaradas como naturais possam atuar. Gerir consistiria, simultaneamente, em deixar fazer, manipular, facilitar, suscitar as condutas dos sujeitos no nível da população, modulando os fenômenos desta, para mantê-los próximos a uma curva de normalidade (Foucault, 2008).
}

Horizontes Antropológicos, Porto Alegre, ano 20, n. 41, p. 303-330, jan./jun. 2014 
como entrada para a compreensão dos modos de operação de tramas mais amplas desse aparato.

O trabalho de campo no escritório foi realizado durante quatro meses, no primeiro semestre de 2012. Busquei etnografar os atendimentos prestados tantos aos refugiados já reconhecidos pelo governo brasileiro, que continuavam a procurar pelos auxílios oferecidos pela agência, como aos que ainda passavam pelo processo de solicitação de refúgio - processo no qual a Casp é um elemento fundamental, como será descrito ao longo deste artigo. Nas primeiras semanas de pesquisa acompanhei o trabalho do atendente da recepção. Tudo o que passava para os setores internos ao escritório era antes triado por esse funcionário, que se empenhava em me explicar como tudo funcionava, desde as legislações e as formas de assistência oferecidas pela Casp e por seus parceiros, até assuntos que envolviam o cotidiano dos solicitantes de refúgio e refugiados fora da instituição. Nos demais setores da organização - Proteção, Assistência e Integração - eu acompanhava os atendimentos conforme era convidada pelas funcionárias do programa. ${ }^{5}$ Pude presenciar entrevistas para pedido de refúgio no setor de Proteção e atendimentos dos mais diversos nos setores de Assistência e de Integração. Somente no setor de Saúde Mental (desativado durante um período e que voltava a se reestruturar no momento da pesquisa) fui impedida de acompanhar os atendimentos.

No começo do segundo mês de pesquisa de campo a coordenação do CAR realizou um treinamento para voluntários ao qual me juntei. Desde esse momento minha entrada foi outra, que me permitiu um contato e uma posição mais estabelecida na agência. A partir daí eu fazia "um pouco de tudo”. Organizava os arquivos, digitava relatórios, pareceres, distribuía doações, esclarecia dúvidas por telefone, ajudava os solicitantes a preencherem o questionário de cadastro no CAR, fazia encaminhamentos para solicitação de documentos, ajudava na organização de atividades em datas comemorativas, participava de reuniões com outros estudantes interessados no trabalho do CAR, auxiliava na triagem da recepção, etc. Assim, cada vez mais pude estar presente em atendimentos ou em conversas que de outra maneira me teriam

\footnotetext{
O programa possui quatro assistentes sociais, sendo que duas não são funcionárias da Casp, mas contratadas por um convênio com o Conare e com o Acnur. Possui ainda duas advogadas, uma psicóloga, uma psiquiatra e uma contadora responsável pelo setor financeiro, além da coordenadora do programa e de uma secretária.
}

Horizontes Antropológicos, Porto Alegre, ano 20, n. 41, p. 303-330, jan./jun. 2014 
sido vetados. A partir de então a minha presença passava a entrar na lógica de funcionamento e organização do trabalho no escritório.

Partindo dessa entrada em campo como voluntária e sendo a proposta deste trabalho a de compreender como instituições como aquela em que eu estava inserida estabilizavam concepções e práticas específicas sobre a população à qual ofereciam determinado cuidado, assistência e, ao mesmo tempo, sobre a qual exerciam um tipo de controle, assumi a posição em que me era permitido acompanhar, principalmente, o trabalho dos gestores. Isso não significou, no entanto, que os refugiados que acessavam o CAR estivessem fora ou alheios à sua configuração. Mas sempre tive em mente que se tratava exatamente disso: uma perspectiva. Outras coisas poderiam ser vistas de outros pontos e a partir de outros métodos de pesquisa, mas tratava-se de um imperativo tático ou condicional (Foucault, 2008): de indicar algumas possíveis linhas de força a se seguir, um determinado regime de visibilidade e o que se pode ver a partir daí. E uma das coisas que me foi permitido visualizar, então, foi um mecanismo de governo. ${ }^{6}$

\section{0 otho do Estado enquanto um mecanismo de governo das populacões}

Em seu curso de 1978, Michel Foucault procurava compreender como o Estado e as práticas de governo dos homens passaram a ser pensadas e levadas em consideração nas práticas destes mesmos homens. Para tanto o autor buscou fazer uma história da razão governamental e do Estado, não como um Estado-coisa, instituição ou substância, mas do Estado presente nas práticas dos homens como um mecanismo de poder. Nesse sentido, o Estado não seria algo que paira acima da sociedade civil, mas antes certa coisa instituída como "Estado" por uma sociedade governamentalizada. Seria, portanto, o efeito das práticas de governo, não o contrário.

Este trabalho também busca pensar práticas de Estado, ou a produção de efeitos de Estado, entendidos como o resultado da produção de determinada forma de governo por organizações, geralmente denominadas state-like institutions, que possuem na maioria das vezes uma forma burocratizada de

6 Entendido como um tipo de exercício de poder, uma técnica de direção das condutas, que incide sobre as populações, possibilitado por um complexo de saberes, instituições, cálculos, táticas, análises e práticas, ao qual Foucault (2008) define como governamentalidade.

Horizontes Antropológicos, Porto Alegre, ano 20, n. 41, p. 303-330, jan./jun. 2014 
atuação. Procurei refletir sobre como esses efeitos de Estado estão presentes no cotidiano da organização etnografada, definida como não governamental, através do aparato burocrático e assistencial que ela põe em funcionamento. Esse empreendimento não visou assinalar um engano de denominação, ou ainda propor uma nova organização entre o que seriam agências estatais ou não estatais, mas apontar o que da perspectiva metodológica adotada foi possível ver: o funcionamento do olho do Estado através desse tipo de organização, enquanto um mecanismo de governo da população alvo de seu programa de assistência, de sua burocracia, e no limite de sua gestão.

Desse modo, o foco do trabalho não está nos sujeitos refugiados, mas antes no modo como ao se institucionalizar, definir, normatizar o refúgio como uma problemática social e política e ao fazer funcionar práticas de cuidado e de controle sobre determinados sujeitos, esses se tornam visíveis para o Estado e para outras organizações, tanto como um problema social quanto como sujeitos que precisam ser governados. Pode-se dizer, portanto, que se trata não de uma etnografia do Estado, mas de um mecanismo - o olho do Estado - e de como determinadas problemáticas e determinados sujeitos são feitos visíveis para as práticas de governo.

A partir da análise da malha de relações que esses sujeitos têm de estabelecer com as diversas organizações com as quais entram em contato ao solicitarem refúgio - o "campo de refugiados sem cercas" - meu objetivo foi o de compreender as formas de funcionamento desse mecanismo de governo.

\section{0 aparato transnacional de governo de populações refugiadas}

A gestão da problemática dos refugiados no Brasil é frequentemente caracterizada na literatura especializada como sendo operada por uma estrutura tripartite (Leão, 2003; Moreira, 2006) no tocante ao acolhimento e assistência a esses sujeitos, formada pelo Acnur, Conare e por ONGs como a Cáritas. Contudo, as formas de atuação desse aparato institucional se dariam de modo diferenciado. Ao Acnur caberia principalmente prover assistência financeira, repassando subsídios à Cáritas. Já o governo brasileiro, representado pelo Conare, teria sua atuação voltada para medidas de proteção, uma vez que delega sobre reconhecer ou não o status de refugiado de um solicitante. $\mathrm{O}$ trabalho da Cáritas é apontado como o mais abrangente, envolvendo, além da assistência e da proteção, o trabalho de integração dos refugiados na sociedade local.

Horizontes Antropológicos, Porto Alegre, ano 20, n. 41, p. 303-330, jan./jun. 2014 
De modo semelhante, a partir da perspectiva que acompanhei etnografando o trabalho dos funcionários do CAR, essa rede de acolhida, assistência, administração, controle das populações refugiadas no país aparece perpassando três esferas organizacionais principais - a agência multilateral da ONU, o governo brasileiro e uma "sociedade civil organizada" - extremamente inter-relacionadas entre si, mas atuando com peso e alcance diferenciados quanto ao que é resolvido ou administrado em cada esfera de atuação institucional específica.

Porém, não presumindo uma suposta verticalidade na qual o Estado seria uma entidade fixa e centralizadora, localizada entre uma esfera internacional e uma sociedade civil local, procurei analisar a forma de operação dessas agências a partir da ideia de um mecanismo transnacional de governo, que permitiria ver órgãos governamentais, organismos multilaterais e organizações não governamentais como contemporâneos e operando no mesmo nível, através de um aparato de governamentalidade (Ferguson, 2006). Nesse sentido, as relações entre essas organizações conformariam uma malha transnacional de entes técnico-burocráticos (Vianna, 2010, p. 92) interconectados:

Pensar em tais organizações como entes técnico-burocráticos não significa afirmar a sua uniformidade enquanto estruturas essencialmente burocráticas - como em geral se imagina uma repartição pública, por exemplo -, mas apenas reconhecer que no estabelecimento das relações com outros atores (ONGs, órgãos governamentais ou agências multilaterais), organizações necessariamente mobilizam saberes técnico-burocráticos, mesmo que em graus variáveis. Desta forma, evita-se fixar o caleidoscópio das organizações, sempre móvel, e enfatiza-se o caráter relacional, do qual depende a atuação das organizações, e os saberes que elas mobilizam a fim de estabelecerem tais relações. (Vianna, 2010, p. 92).

Não se trata, no entanto, de tomar essas organizações como atores com a coerência, agência e autonomia que o termo ente, por exemplo, poderia presumir. $\mathrm{O}$ que procurei compreender foi como essas instituições em suas inter-relações criam um efeito estrutural (Mitchell, 2006), ou seja, como são produzidas como entidades aparentemente separadas e independentes pelos mecanismos de poder que nelas atuam. O próprio Estado, assim, aparece como um efeito estrutural desse tipo: não como uma estrutura de fato, mas como um poderoso efeito de práticas que fazem estruturas aparentarem existir como entidades. 


\section{A. agência multilateral da ONU: o Acnur}

Segundo Jubilut (2005, p. 97), a cooperação entre a Casp e o Acnur para promover assistência aos refugiados é fruto de uma dupla tradição: "por parte da Igreja Católica a tradição de se ocupar da questão dos excluídos, entre os quais a população refugiada, e por parte do Acnur a tradição de buscar organizações locais para serem suas agências implementadoras”. Os principais objetivos dessa agência seriam os de providenciar a proteção aos refugiados e promover a implementação do que determina como soluções duráveis: repatriamento, integração local e reassentamento.

Para realizar tais objetivos o Acnur atua diretamente em situações caracterizadas pela agência como emergenciais, tais como territórios em guerras civis ou regiões em que ocorreram desastres naturais. Nas situações consideradas como não emergenciais, em alguns territórios de recepção de refugiados, por exemplo, a atuação é feita por meio de trabalhos de cooperação com as agências e governos locais, recorrendo principalmente à cooperação com ONGs que estejam mais próximas da realidade local. Estas se tornam suas agências implementadoras, que por meio da coordenação e do financiamento do Acnur vão desenvolver seus três programas: proteção, assistência e integração.

No cotidiano dos atendimentos aos refugiados e solicitantes de refúgio no CAR a atuação do Acnur é pouco perceptível. Onde mais se nota sua "presença” é nos cartazes, pôsteres e quadros de campanhas da agência que decoram todo o escritório. Sua ação acaba sendo indireta, através dos financiamentos para os projetos: a assistência humanitária do Acnur chega aos refugiados e solicitantes através do auxilio para transporte, para a compra de remédios, das cestas básicas, pela manutenção dos programas de saúde mental e de proteção. No entanto, aos refugiados e solicitantes em si só é possível apreender a atuação da Casp, que é quem realiza diretamente o trabalho de assistência a partir do financiamento externo.

No que se refere aos funcionários, porém, o relacionamento com o Acnur é sempre apontado como muito bom e próximo, constituindo uma dimensão importante para o trabalho que é realizado no CAR. Segundo as advogadas, por exemplo, o Acnur não só é a agência que paga seus salários, mas é quem faz todo o seu treinamento para o atendimento e mantém ainda um estreito contato para o esclarecimento de dúvidas sobre esse atendimento e na elaboração dos pareceres de cada pedido de refúgio.

Horizontes Antropológicos, Porto Alegre, ano 20, n. 41, p. 303-330, jan./jun. 2014 
Apesar de umas das funções definidas do Acnur ser a de coordenar os projetos desenvolvidos pelas agências implementadoras, a relação dessa agência com os funcionários do CAR acaba sendo próxima daquela que é estabelecida entre este e as organizações da sociedade civil também atuantes na causa do refúgio: a de parceria. Isso se deve, principalmente, a certa consonância entre os valores que guiam o trabalho no CAR e aqueles estabelecidos pelo Acnur em sua atuação. Ambos estão ligados principalmente à noção de que o trabalho realizado deve ser humanitário. O caráter de parceria se estabelece por estarem em um mesmo regime de valores.

Em seu pronunciamento em comemoração ao dia mundial do refugiado do ano de 2008, por exemplo, o então alto comissário das Nações Unidas para o Refúgio afirmava que o trabalho do Acnur estaria focado na proteção dos direitos e bem-estar dos refugiados e também em assegurar o acesso à segurança, à assistência humanitária, ao apoio em longo prazo e em soluções duradouras para que estes sujeitos pudessem reconstruir suas vidas. Ele encerra seu pronunciamento dizendo que garantir que os refugiados obtenham a proteção que merecem é uma causa nobre porque os direitos dos refugiados são direitos humanos - direitos que pertencem a todos nós. É possível notar em sua fala como o trabalho da agência parte da noção de que o trabalho desta deve atuar na recuperação dos direitos dos refugiados enquanto seres humanos. Perspectiva que também informa não só o trabalho da Casp enquanto agência implementadora do Acnur, mas as organizações da "sociedade civil organizada” pela causa do refúgio de modo geral, conformando um dos pontos fundamentais no referido regime de valores dessas instituições.

\section{0 aparato estatal: a Policia Federal e o Conare}

A gestão realizada em âmbito estatal se dá, principalmente, em duas instituições: na Polícia Federal e no Conare. A relação entre os funcionários e essas organizações é bastante diferente da que é estabelecida com o Acnur. Nos regimes de valores que estão em jogo na relação entre essas agências não está mais marcado o "humanitarismo", mas principalmente as noções de "segurança nacional” e de "administração".

Na Casp o relacionamento com a Polícia Federal é sempre apontado como instável, tendo períodos de maior ou menor cooperação entre as instituições:

Horizontes Antropológicos, Porto Alegre, ano 20, n. 41, p. 303-330, jan./jun. 2014 
Tem fases em que a gente faz reuniões com eles, aproxima muito a relação. Fica fácil. A gente liga, eles respondem, resolvem. Tem fases que não. E tem muita Policia Federal também no interior, que não conhece a gente e agora começam a receber solicitantes de refúgio e refugiados. Não sabem o que fazer, porque é um fato novo lá. E aí é um pouco difícil esse contato. Quando a gente liga [dizem] “Que é? Uma ONG querendo me dar ordens?” E depois com o tempo, como a gente acaba ajudando, aí eles entendem que a gente não está querendo nada mais do que as funções, as obrigações deles. Acaba melhorando com o tempo. Mas com a Polícia Federal é um pouco complicado. (Advogada do CAR).

Nos meses em que realizei o trabalho de campo no CAR a relação estava conturbada devido a cancelamentos sem aviso prévio de muitas entrevistas para solicitação de refúgio já agendadas e de denúncias sobre pessoas que estariam ficando retidas por semanas nos aeroportos, em uma área restrita e com poucos recursos, denominada pelos funcionários como "conector”. As tentativas da Casp de intermediar situação não estariam sendo "bem vistas":

Porque a gente não pode se meter de uma forma direta. Porque não é a nossa função. A função da Cáritas é, chegou aqui dentro do escritório, a gente presta o auxílio. Se a pessoa está presa no aeroporto, a Polícia Federal está fazendo um serviço de investigação sobre aquela pessoa. Se a gente fica insistindo com a Polícia Federal de que tem que retirar ele de lá, a gente cria um atrito direto com ela. (Advogada do CAR).

Em casos assim é preciso saber manter a relação "diplomaticamente”, diz a coordenadora do CAR, para que cada um possa realizar suas respectivas funções.

A Polícia Federal tem o seu eixo na segurança pública. Então todo estrangeiro imigrante ou refugiado - é supostamente uma pessoa que pode ferir a segurança nacional. Então eles tomam muitos cuidados. E esse excessivo cuidado, muitas vezes deixa alguém, que é solicitante de refúgio, lá na Polícia Federal esperando eles fazerem uma investigação que pode ser demorada. Eles ficam lá às vezes por um tempo muito longo, até que eles liberem. A gente tem tido um bom relacionamento. Só que eles alegam isso: "Olha, é questão de segurança. Eu não posso deixar qualquer pessoa entrar.” $\mathrm{E}$ a gente acha isso ruim, porque a gente gostaria que eles fossem mais ágeis e aqueles que não estão ferindo a segurança nacional, que eles liberassem com mais rapidez. [...] Eles trabalham da maneira 
deles, alegando a segurança nacional. E nós preservamos os direitos humanos dos solicitantes de refúgio.

Já em relação ao Conare, o relacionamento é apontado como "profissional”, “administrativo” ou "burocrático”.

A nossa relação com eles é basicamente administrativa. O contato que eu tive com o pessoal do Conare foi superprodutivo. Foi bem administrativo mesmo, mas foi superpositivo. [...] A gente tem aí uma boa comunicação de forma geral. Com o Ministério da Justiça, que é um órgão a que nós estamos de certa forma subordinados, é a mesma questão administrativa do Conare. Que é um órgão específico do Ministério da Justiça. (Advogada do CAR).

No que a gente precisa eles dão apoio. Cada um dentro da sua estrutura [...]. Só que tem um número limite de funcionários. Então às vezes uma coisa que você precisa de urgência não sai na hora. Mas são coisas burocráticas. (Coordenadora do CAR).

Também para os refugiados e solicitantes de refúgio a relação é muito burocratizada e gera constantes conflitos. "Práticas burocráticas são mecanismos cruciais pelos quais o efeito deslocador do Estado é produzido e reproduzido” (Sharma; Gupta, 2006, p. 17, tradução minha), isto é, práticas nas quais o aparato estatal é reificado como algo externo e superior às práticas cotidianas dos sujeitos. "Brasília" ou a "Federal" se apresentam como algo distante do cotidiano dos solicitantes de refúgio e dos refugiados, mas que ao mesmo tempo definem sua legalidade ou não no país, através da garantia da documentação. Sempre é muito complicado para os solicitantes de refúgio, principalmente, entenderem que quem autoriza a emissão de seus documentos não é a Casp, com quem estão lidando cotidianamente, mas sim o Conare, cujo único contato direto se dá através dos advogados que fazem a entrevista que irá compor o parecer sobre cada caso.

Ter que resolver uma questão com o Conare, e mesmo com o Acnur, é geralmente visto como um problema, pois pode gerar demora nos atendimentos ou na resolução de alguma outra atividade cotidiana. Solucionar alguma demanda fora da esfera do CAR implica certa falta de visibilidade do percurso todo do processo, não só para os refugiados, mas muitas vezes para os próprios funcionários. 


\section{A atuação da sociedade civil: as parcerias}

Uma grande especificidade no caso brasileiro de governo das populações refugiadas em seu território é a presença marcante de uma "sociedade civil organizada na causa do refúgio", como costumam se denominar, no que se refere ao processo de acolhida e atendimento desses sujeitos.

Destacam-se os trabalhos realizados pelas Cáritas Arquidiocesanas de São Paulo, Rio de Janeiro e Manaus e pelo Instituto Migrações e Direitos Humanos, que compõem centros de atendimento a estas pessoas, como o CAR. Porém, existe toda uma rede de parcerias com albergues, associações, ONGs, sem a qual esses centros de atendimento não conseguiriam manter todo o trabalho de assistência que procuram oferecer. Isso é muito evidente no caso de São Paulo, na Casp, que possui uma estrutura de escritório, auxiliando os refugiados com assuntos burocráticos e assistenciais, mas não possui, por exemplo, uma estrutura de albergamento ou que ofereça alimentação. Para isto contam com as parcerias.

As organizações parceiras constituem uma rede muito ampla, que vai desde institutos de pesquisa, cooperativas e associações comunitárias, até empresas e agências internacionais. Dentro do setor de integração do CAR, por exemplo, muito pouco poderia ser realizado sem as parecerias com o chamado "sistema S" - Sesc, Sesi, Senai, Senac - para a capacitação profissional e educacional dos refugiados. Da mesma forma, a assistência com moradia, que é uns dos pontos apontados tanto pelas assistentes sociais como pelos refugiados como o mais problemático, estaria ainda mais debilitado sem os albergues parceiros da sociedade civil.

Os órgãos estatais ou as agências internacionais não estão alheios ao trabalho de assistência, mas delegam grande parte do serviço assistencial e mesmo burocrático às entidades civis. Ações humanitárias, de sensibilização, de solidarização e de conscientização da população local, assim como do próprio governo brasileiro, são as principais formas de atuação dessas organizações parceiras. Configuradas enquanto uma "sociedade civil organizada” pela causa do refúgio, elas são os principais sujeitos políticos atuantes não só pelas demandas assistenciais e de integração dessa população no país, mas também pela causa da recuperação de seus diretos de cidadania.

O estatuto do refúgio, desde o início de sua institucionalização e normatização jurídica, destaca-se como uma problemática que precisaria ser

Horizontes Antropológicos, Porto Alegre, ano 20, n. 41, p. 303-330, jan./jun. 2014 
pensada dentro de certa transnacionalidade, mais do que a partir das inter-relações e transformações entre um nível local e outro global. Organizações como a Cáritas dificilmente podem ser enquadradas em um contexto local, nacional, ou mesmo internacional de atuação. Daí a importância de analisar seu trabalho como parte de um aparato transacional de governo, no qual uma multiplicidade de determinações são produzidas e articuladas em arranjos específicos de relações.

No entanto, tais arranjos articulados formam compósitos nos quais determinados discursos e práticas são estabilizadas, sem que sejam redutíveis a uma única lógica de funcionamento. As organizações, com seu efeito estrutural, são apenas os espaços em que esse processo de estabilização se dá de forma mais evidente. O caráter transnacional desse aparato, portanto, se produz em razão de sua capacidade de territorializar e ao mesmo tempo de deslocar determinados fenômenos através de diversas esferas organizacionais e situações específicas formando compósitos de relações, mas sem fixá-los de modo final.

Na sessão seguinte, procuro discutir os efeitos da territorialização particular desse aparato transnacional de governo operada pelo trabalho do CAR, através do mecanismo que aqui denominei de olho do Estado.

\section{A producão do refugiado como um sujeito visivel para o olho do Estado: a esfera burocrático-administrativa}

Enquanto um "centro de referência” para os refugiados e solicitantes de refúgio, o CAR funciona como um escritório onde se lida principalmente com assuntos burocráticos - solicitação de documentos, encaminhamentos, recursos, atendimento jurídico, legislações, prazos, formulário, relatórios, etc. Tem de lidar com a esfera da administração burocrática que envolve a entrada e estabelecimento de uma pessoa em um país que não é o de sua nacionalidade.

Desde que entram no país, o contato constante com uma Cáritas torna-se parte integrante na vida dos solicitantes de refúgio. No cotidiano do CAR é possível perceber como a Casp é uma intermediária inescapável nas relações entre os refugiados e os órgãos governamentais, ONGs, empregadores, etc. Para praticamente cada ação dessas pessoas é necessária uma “declaração” ou um "encaminhamento" vindo da Casp. Ao entrarem no Brasil os solicitantes de refúgio entram também em uma malha de relações burocrático-administrativas 
específicas, que, conjuntamente com o trabalho assistencial-humanitário oferecido pelos programas do escritório, vai constituir esses sujeitos enquanto uma população singular, que poderá, então, ser alvo da intervenção de um mecanismo de governo.

A entrada dos solicitantes de refúgio no Brasil tem se dado através de quatro maneiras principais: ilegalmente, via fronteira terrestre; legalmente (com um visto de turista ou de estudante), de avião; ilegalmente, de avião; ilegalmente, de navio. O que deveria acontecer depois da entrada no país de acolhida é que essas pessoas contatassem a Polícia Federal para solicitar o refúgio. Geralmente, muitos já se informaram em seus países sobre como se dá a solicitação de refúgio no Brasil e já entram em contato com uma Cáritas assim que chegam, por saberem que elas são agências intermediárias nesse processo. Já para os que chegam ilegalmente nos aeroportos não há escapatória: ficam retidos no setor de imigração e, se conseguem solicitar refúgio, são encaminhados às Cáritas.

Quando chega à Casp e informa que deseja solicitar refúgio, o "caso novo” tem uma primeira conversa rápida com uma das advogadas que, tendo identificado um possível caso de refúgio, pedem que ele preencha uma ficha com informações básicas, para que possa ser cadastrado no sistema da agência. Essa identificação de um "caso de refúgio", no entanto, não é tão simples e imediata:

Toda pessoa que chega aqui na Cáritas e fala "eu quero pedir refúgio”, eu sou obrigada a deixar a pessoa [solicitar]. É um direito do estrangeiro, pedir refúgio. Algumas vezes a gente tenta explicar, falar "olha não é caso de refúgio, você pode ir buscar outros lugares". A gente indica e às vezes a pessoa [fala] "OK, não é caso, não vou pedir" e vai embora. Tem gente que bate o pé e fala "eu quero mesmo assim”, porque eles sabem que vão ficar legais no país por quase um ano [...]. Em geral eu só falo "olha, não é caso" para a pessoa que fala "eu vim para trabalhar”. E pelo contexto do país realmente é óbvio que não é caso [de refúgio]. Mas mesmo assim se a pessoa bate o pé e fala "eu quero pedir", eu sou obrigada a deixar porque é um direito deles. Então a Cáritas atende todo mundo que pede. Todo mundo que chega aqui e fala "eu quero pedir refúgio". (Advogada do CAR).

Posteriormente, a secretária do CAR entra em contato com esse solicitante para informá-lo do dia em que deverá comparecer na Polícia Federal 
para uma entrevista na qual precisará “prestar declarações” sobre as razões pelas quais solicita refúgio, as circunstâncias de sua entrada no Brasil, e para fornecer algumas informações pessoais Sem o "termo de declarações” feito pela Polícia Federal, o caso não pode ser encaminhado para o Conare, onde começa o processo de solicitação de refúgio propriamente dito.

No dia da entrevista na Polícia Federal, o solicitante precisa ir antes ao CAR para buscar um "encaminhamento" feito pelas assistentes sociais. E feito o "termo de declarações” na Polícia Federal, ele deve voltar ao CAR, agora para preencher um questionário mais detalhado sobre sua situação para ser enviado ao Conare. Nenhuma orientação sobre como se portar nessa entrevista com a Polícia Federal pode ser feita pelas assistentes sociais ou qualquer outro funcionário. Mesmo no questionário que em seguida é preenchido na CAR, não se pode orientar os solicitantes sobre o que escrever. Nesse questionário é preciso "aparecer a situação real” da motivação do pedido de refúgio. $\mathrm{Na}$ Polícia Federal é importante que o caso não se apresente como algo que ponha em risco a "segurança nacional”. Já no CAR ele precisa ser apreendido como passível de ser categorizado juridicamente como um caso de refúgio.

Tendo preenchido o questionário, as assistentes sociais podem dar entrada no pedido do "protocolo provisório", que será sua documentação até que seja promulgada a decisão final sobre seu pedido de refúgio. Quem expede este documento é a Polícia Federal, mas antes ele deve ser autorizado pelo Conare. É a Casp que entra em contato com este pedindo tal autorização e é para a Casp que ela é enviada. Com o aumento da demanda de solicitações de refúgio no período da pesquisa, as autorizações demoravam até um mês para chegar ao CAR. Se antes as assistentes sociais procuravam entrar em contato com os solicitantes para avisar da chegada da autorização, com o aumento do número de pedidos, cada vez mais eles mesmos vinham ao escritório para saber se a autorização já havia sido enviada, o que gerava muitos conflitos. Elas diziam que não adiantava vir ao escritório, pois isso atrasava os demais atendimentos, que era melhor ligarem ou esperarem que as assistentes sociais entrassem em contato. Eles por sua vez reclamavam da demora e muitas vezes não compreendiam que “o problema é em Brasília”, que não era a Casp, mas o governo brasileiro quem emitia a declaração autorizando a expedição do protocolo.

Com o protocolo em mãos é agendado para esse solicitante um horário com a assistente social do setor de integração, que lhe dá um encaminhamento

Horizontes Antropológicos, Porto Alegre, ano 20, n. 41, p. 303-330, jan./jun. 2014 
para que possa fazer a carteira de trabalho e posteriormente um CPF, nos órgãos responsáveis por essa documentação. Assim como o protocolo, enquanto documentos provisórios, a carteira de trabalho precisa ser renovada a cada três meses, até que seja deferido ou negado o pedido de refúgio. Para cada renovação, o mesmo procedimento: agendar um atendimento, pegar o encaminhamento, ir ao órgão responsável pela emissão do documento, voltar ao CAR para o próximo procedimento.

Em meio a esse percurso de pessoas e de documentos por entre instituições, os solicitantes de refúgio, a cada nova documentação que obtêm, vão sendo produzidos como sujeitos específicos perante o Estado brasileiro: sujeitos passíveis de serem categorizados e reconhecidos dentro do status jurídico de refugiado. E cada organização pela qual passa acessa uma parte apenas da composição que conforma esse sujeito refugiado, por isso precisam trabalhar em interdependência. Sem o encaminhamento do CAR, a Polícia Federal não compreende esse sujeito como um solicitante de refúgio, mas genericamente como estrangeiro. Sem o termo de declarações, enviado pela Casp, o Conare não inicia o processo de solicitação de refúgio, pois tal estrangeiro genérico não se inclui em sua alçada administrativa específica. E, enfim, sem a autorização do Conare para a emissão do protocolo provisório, em papel timbrado, carimbado e assinado pela Casp, a Polícia Federal não emitirá o documento para esse solicitante. Consequentemente, ele não existirá enquanto refugiado perante o Estado brasileiro e não poderá receber a assistência humanitária da Casp ou do Acnur.

Feita essa primeira documentação provisória e as entrevistas na Polícia Federal e na Casp, os solicitantes aguardam que um advogado representante do Conare venha à Casp realizar uma das partes do parecer sobre seu caso. Posteriormente, esse advogado relata seu parecer a um Grupo de Estudos Prévios (GEP), formado por representantes dos ministérios que compõem o Conare, ${ }^{7}$ por um representante do Acnur e um representante da sociedade civil. As partes do GEP elaboram um parecer sobre o caso e o apresentam na reunião plenária do Conare.

O Conare é composto pelos ministérios da Justiça, das Relações Exteriores, do Trabalho e Emprego, da Educação e da Saúde. Também participa do comitê o departamento de Polícia Federal.

Horizontes Antropológicos, Porto Alegre, ano 20, n. 41, p. 303-330, jan./jun. 2014 
Como me disse um refugiado, “a burocracia não acaba nunca”. O atendente da recepção do CAR tem uma justificativa para isso: "Essa burocracia toda dá muito trabalho para a gente, mas é uma forma de ter um controle. Se não eles desaparecem.” Uma voluntária também fez uma observação interessante sobre a presença constante dos solicitantes no escritório por conta da documentação e da assistência que este oferece que ajuda a entender o que caracteriza este mecanismo de governo: "É como se fosse mantido um campo de refugiados, só que sem as cercas. Só através da burocracia.”

Tanto a fala do atendente quanto a da voluntária evidenciam um problema para essas organizações que lidam com os refugiados: como enxergá-los como uma população específica em meio à população nacional? Como fazer com que esses sujeitos apareçam, não só para o programa de assistência da Casp, mas também que sejam legíveis para o olho do Estado? O efeito produzido por essa malha burocrático-administrativa é criar sujeitos legíveis, que sejam mantidos não em um campo de refugiados com cercas, mas em um campo de visibilidade determinado. Esse é seu mecanismo de governo.

Pensando sobre a forma como o Estado acessa a população que busca governar, Scott (1998) destaca a produção de um mecanismo de legibilidade como a condição primordial para qualquer intervenção estatal. Tal mecanismo requer a invenção de unidades que sejam visíveis e padronizáveis. Um documento de identidade ou uma ficha de cadastro confere essa existência a um sujeito perante o Estado. A burocracia é uma forma de tornar os sujeitos legíveis em meio a uma realidade complexa que o aparato estatal por si só não consegue acessar diretamente. Trata-se de um processo de simplificação da complexidade dessa população, que, no entanto, torna o fenômeno que está no centro do campo de visão mais acessível e ainda mais suscetível a uma mensuração cuidadosa. O procedimento burocrático produz um mapa, uma forma de escalonar e categorizar uma população não por um processo de redução de sua complexidade, mas recortando-a, estabilizando-a e fixando-a. Tal procedimento permite que essa população se torne visível.

Se aprovado o pedido de refúgio, o solicitante se registra junto à Polícia Federal para receber seu Registro Nacional de Estrangeiro e assina um "termo de responsabilidade” vindo do Conare - ele já é legível como “refugiado”. Se o pedido é indeferido o solicitante tem um mês, desde sua notificação, para sair do país ou para entrar com um recurso perante o Ministério da Justiça. 
Uma das advogadas do CAR explica o que acontece "na prática”, quando um pedido é indeferido:

Aí, dizem que ele não é refugiado. Ele volta aqui e eu o ajudo a preparar um recurso para ser enviado ao Ministério da Justiça. A palavra final é do ministro da Justiça. Se também é pelo indeferimento, aí qual é a situação do refugiado? Ele é comunicado pela Polícia Federal que tem um prazo para deixar o território brasileiro. [...] Eles recebem esse comunicado, "se você não deixar o país, você vai passar por um processo legal de deportação”. E o que acontece na prática? Na prática essa pessoa acaba sumindo no território brasileiro, porque o governo não tem verba para fretar um avião e deportar todo mundo que está numa situação ilegal [...]. Essa pessoa fica aqui em uma situação de limbo jurídico [...]. A possibilidade dela é se casar com brasileiro, ter filho brasileiro. E aí ela entra em um processo de solicitação dos documentos por causa disso.

Ficar no "limbo jurídico" é não ser visto pelo mecanismo do olho do Estado. "Na prática” esse sujeito desaparece porque a burocracia acionada por esse aparato de governo, apesar de constituir um determinado mapa de visibilidade, é um mecanismo que enxerga mal e parcialmente. Não é todo recorte da "prática" que a burocracia consegue estabilizar e administrar, mantendo a visibilidade de seus elementos organizados. Há dimensões do "real” como chama Scott, ou da "prática" como diz a advogada, que lhe escapam o tempo todo. Seu mapa é sempre parcial e representa apenas a parte do real que interessa à observação estatal (Scott, 1998). A dimensão burocrático-administrativa precisa de outros mecanismos que operem juntamente a ela para produzir esse sujeito plenamente visível e, logo, melhor governável.

\section{A producão do refugiado como um sujeito de direitos pleno: a estera assistencial-humanitária}

Documentos, relatórios, fichas cadastrais jogam luz e permitem acessar apenas uma parcela da complexidade que conforma a população específica que procuram categorizar e padronizar a partir das simplificações que estabilizam. Outra dimensão fundamental desse mecanismo de constituição do sujeito refugiado visível elaborada pelo trabalho do CAR é a esfera assistencial-humanitária.

Horizontes Antropológicos, Porto Alegre, ano 20, n. 41, p. 303-330, jan./jun. 2014 
Na Casp a assistência aos refugiados e solicitantes de refúgio é dividida em três setores, estabelecidos a partir do programa definido pelo Acnur para suas agências implementadoras locais: proteção, assistência e integração. Como destaca o representante do Acnur no Brasil, "ao ser reconhecido, o refugiado recebe inicialmente a proteção expressa de maneira formal em um documento. É o reinício de sua cidadania.” (Varese, 2006, p. 9). Porém, é no atendimento dentro dos programas assistenciais do CAR que essa dimensão burocrático-administrativa descrita acima se cruza e se conecta com os valores da dimensão humanitário-assistencial, constituindo sujeitos visíveis a partir de outra categorização que não a jurídica apenas (expressa em uma documentação), mas como sujeitos de direito, considerados passíveis de se tornarem cidadãos plenos.

\section{Protecão}

O primeiro setor que tais sujeitos acessam é o de Proteção. Basicamente o setor de assistência jurídica aos refugiados e solicitantes, composto pelas duas advogadas do CAR. No procedimento de solicitação de refúgio em si, as advogadas do programa são responsáveis por realizar a entrevista que vai compor o parecer sobre cada caso, elaborar a parte do parecer que corresponde à avaliação da Casp sobre os casos e defendê-los no GEP, como descrito acima. Em casos de pareceres negativos as advogadas auxiliam o solicitante na elaboração de um recurso. Esse é um setor de atuação marcadamente jurídica, mas do qual as questões assistenciais não estão alheias, uma vez que são as advogadas que muitas vezes conhecem detalhes da vida pregressa dos solicitantes de refúgio através das entrevistas que realizam, e esse fator tem peso para que o atendimento não seja estritamente burocratizado.

O setor de Proteção é onde primeiramente as dimensões burocrático-administrativa e assistencial-humanitária se atravessam, criando em seus encontros um compósito que é o sujeito refugiado. Esse programa legitima a categoria jurídica de refugiado e confere a esse sujeito a possibilidade de uma documentação que o identifica e ainda permite que seja incluído como beneficiário dos demais auxílios oferecidos pela Casp. É a partir do momento em que esse sujeito é categorizado como refugiado, ou provisoriamente como solicitante de refúgio, que ele pode ser visto como um alvo da intervenção assistencial e humanitária do CAR.

Horizontes Antropológicos, Porto Alegre, ano 20, n. 41, p. 303-330, jan./jun. 2014 


\section{Assistência}

Já o setor de Assistência busca auxiliar os refugiados e solicitantes de refúgio a suprirem principalmente suas necessidades mais imediatas com saúde, moradia e alimentação. Também distribui as roupas, sapatos e cobertores, fraldas e leite em pó, comprados com o financiamento vindo de projetos com o Conare e com o Acnur.

A Casp oferece ainda um auxilio de subsistência financeira por três meses. Os beneficiários desse auxílio, ao qual os gestores se referem como "sub", são pessoas cujo caso caracteriza-se como de "alta vulnerabilidade”, como mulheres desacompanhadas, mulheres desacompanhadas que são chefes de família, idosos, portadores de doenças crônicas ou em tratamento, famílias cujos pais estão desempregados, grupos como maior dificuldade de integração. Porém, são as assistentes sociais, em conjunto com as advogadas, psicóloga e psiquiatra, que determinam os critérios de distribuição do auxílio, conforme as situações e os casos que se apresentam no momento em que chega "o dinheiro do projeto".

A gente tem um recurso, muito pouco, do governo brasileiro para casos de alta, altíssima vulnerabilidade. [...] [Qual] então, o critério que a gente tem pra quem a gente vai ajudar? A Vanessa que está desempregada e passou por uma cirurgia e precisa de ajuda, [pois] não está conseguindo emprego, por conta disso? Mas chegou a Laurette que está em uma gravidez de risco, não pode trabalhar de jeito nenhum, e aí? Então a gente tem que ter, assim, o critério, do critério, do critério, porque é muito pouco pra ajudar essas pessoas. [...] Então a gente sempre senta com o social, a saúde mental, também o jurídico, para analisar. Elas apresentam um caso: "A pessoa me relatou isso, isso, isso." "Não vamos fazer assim, vamos fazer assado". "Vamos pedir aqui, vamos pedir ali.” (Coordenadora do CAR).

Outra parte do parecer, no entanto, deve declarar que o beneficiado está, quando possível, buscando sair da situação de vulnerabilidade em que se encontra. Um grupo de butaneses que não consegue encontrar trabalho devido a dificuldades com o idioma, caracterizando um grupo com dificuldades de integração, deve estar cursando aulas de português. Uma mãe desacompanhada deve matricular seus filhos em um escola para que possa trabalhar.

Devido ao caráter muitas vezes emergencial desses auxílios, os solicitantes de refúgio são os mais beneficiados por eles. Além dos trâmites que 
envolvem o pedido do protocolo provisório (também realizados no setor, apesar de não serem procedimentos que compõem diretamente o programa de assistência), os solicitantes e refugiados procuram o setor por três questões principais: saúde, moradia e alimentação.

Desde o momento em que recebem seu protocolo provisório, os solicitantes de refúgio já podem utilizar as Unidades Básicas de Saúde do sistema público. Assim como hospitais públicos ditos parceiros e serviços de saúde organizados pela sociedade civil, como o tratamento odontológico oferecido pelo Sesc. A Casp fornece ajuda financeira para pagarem as passagens de ônibus e metrô necessárias para que cheguem ao local da consulta e para os remédios que for preciso comprar. O próprio CAR possui uma psicóloga e uma psiquiatra, ambas contratadas através de convênio firmado com o Acnur. Porém, para os casos mais graves contam com a parceria com o Instituto de Psiquiatria do Hospital das Clínicas.

Conseguir moradia para os que acabaram de chegar e não possuem nenhum contato no Brasil, por outro lado, é a principal dificuldade das assistentes sociais. Isso porque o CAR não possui uma estrutura de albergamento e nos albergues parceiros as vagas são pouquíssimas se comparadas ao número de necessitados. Não são raros os casos de pessoas que passam o dia esperando por uma vaga em um albergue, não conseguem encontrar e acabam passam a noite na rua. Uma segunda opção é encaminhá-los para o programa da Tenda Social do Parque Dom Pedro, no centro de São Paulo, onde depois de uma triagem são encaminhados para albergues públicos. Neste caso, as assistentes contam que muitas vezes os solicitantes preferem ficar na rua, pois enquanto os albergues parceiros têm um público específico - migrantes -, os albergues públicos "têm todo tipo de gente”, dizem, e os solicitantes costumam sentir-se incomodados.

Duas são as formas de assistência com alimentação. Se o solicitante ou refugiado morar longe do centro de São Paulo a Casp pode fornecer-lhe uma cesta básica mensal, a qual eles vêm retirar no escritório. A outra opção é fazer um cartão de alimentação do Sesc-Carmo, localizado a alguns quarteirões da Casp, que possibilita refeições a baixo custo no restaurante da instituição. Esse último auxílio só é permitido para aqueles que ainda não possuem o visto que permite a permanência definitiva no Brasil.

Proporcionando-lhes moradia, alimentação e saúde, mais do que simplesmente oferecer um auxílio, o programa do CAR produz este refugiado com um sujeito de direitos perante o Estado brasileiro. Um efeito do programa 
de assistência, portanto, é o de buscar criar sujeitos que possam se tornar cidadãos plenos. No entanto, se o setor de proteção confere determinados direitos civis a esses sujeitos e o de assistência busca prover seus direitos sociais, os direitos políticos que conformariam o cidadão pleno de fato, almejado pelos gestores da Casp, por militantes da sociedade civil e pelo próprio aparato estatal, só são alcançados depois de anos e do trabalho constante do setor de Integração para que esse sujeito de direito não volte a "desaparecer", se tornando ilegível para o olho do Estado.

\section{Integração}

O programa de integração está focado em duas questões principais: trabalho e educação. Segundo a assistente social responsável pelo setor, este foi pensado com o objetivo de "criar e prover a independência do refugiado e do solicitante de refúgio", mas o trabalho no setor também consistiria em "trazer a sociedade para junto da gente”. E isso fica claro quando se observa o principal modo de operação desse programa: as parcerias. Enquanto os convênios são definidos pela coordenadora do CAR como "acordos em que rola dinheiro” com órgãos governamentais e com o Acnur, as parcerias são fechadas em um intenso e constante trabalho de "negociação”, “conscientização”, "sensibilização" e "solidarização" com os parceiros.

Como no setor de Assistência, o setor de Integração não escapa à parte mais burocrática do trabalho, pois nele é feito o encaminhamento para que o solicitante possa fazer uma carteira de trabalho e um CPF. Esse programa, no entanto, adiciona mais dois elementos à composição do refugiado como sujeito de direito pleno, que são suas principais frentes de atuação: a busca por trabalho (formal) e a formação educacional.

Muitas vezes, devido ao problema do idioma, é mais difícil que os solicitantes e refugiados consigam empregos por conta própria. Por essa razão a assistente social responsável pelo setor ajuda-os a agendarem entrevista em seleções e projetos organizados por parceiros. A própria assistente social muitas vezes ajuda-os a elaborar um currículo, para que possam participar das entrevistas de emprego oferecidas pelas agências e centros de auxílio ao trabalhador parceiros ou conseguidas por conta própria.

No momento desta pesquisa, a maioria das vagas disponíveis era para serviços de nível técnico e na construção civil. E quanto maior o grau de

Horizontes Antropológicos, Porto Alegre, ano 20, n. 41, p. 303-330, jan./jun. 2014 
formação mais difícil era para que a pessoa conseguisse um emprego em sua área, por não poder comprovar, muitas vezes, essa formação. Geralmente passavam por diversas entrevistas até serem selecionados para alguma vaga e enquanto não conseguiam um emprego formal, muitos iam "se virando", como diz o atendente da recepção do CAR, através do comércio informal. Segundo a assistente social responsável pelo setor, porém, a agência procura realizar todo um trabalho de conscientização para o trabalho formal:

Por exemplo, teve um que chegou para mim e falou assim "pela primeira vez na minha vida eu estou trabalhando", porque tinha um registro na carteira. Eu falei: “Não, amigo, no seu país você trabalhava. Só que é diferente.” Aqui nós temos uma legislação e a obrigatoriedade de um trabalho mais formal. Tem muita informalidade ainda, que é o que a gente quer quebrar. Porque se ele já vem de lá para cá, sem nenhum comprovante de trabalho e continua se sujeitando a fazer bico, ou a trabalhar, sabe... ilegalmente, nunca vai ter uma empresa que chegue para ele e fale “não, esse daqui eu vou pegar”. E a gente cria essa sensibilização para o trabalho formal para que ele expanda o trabalho aqui. Se ele tiver um primeiro registro e der continuidade aos estudos, à formação dele, ele tem a tendência a crescer.

Outro motivo para que a instituição incentive o trabalho formal é que não fiquem "na rua", encarada como um espaço perigoso de trabalho para os estrangeiros, mesmo documentados e com sua situação legal no país regularizada.

Desde o primeiro momento em que chegam ao Brasil, a procura por trabalho é uma das principais motivações para que os solicitantes de refúgio e refugiados procurem o CAR. A busca por uma documentação que permita que tenham sua situação legalizada está estreitamente vinculada, para muitos, à questão de quererem trabalhar.

Como citado acima, a outra frente de atuação do setor está relacionada à educação. Em relação a essa questão, o trabalho da assistente social nesse setor consiste principalmente em encaminhar refugiados e solicitantes aos cursos que lhes interessem, sendo maior a oferta de cursos técnicos e profissionalizantes. As principais parcerias que oferecem cursos técnicos aos refugiados, e também educação formal, são aquelas do chamado "sistema S”. Existe ainda o projeto com universidades públicas federais que reservam vagas em seus vestibulares para refugiados já reconhecidos. 
Todos os projetos e programas acima são voltados para os refugiados apenas. Mas em certo momento, conta a assistente social do setor de Integração, sentiu-se a necessidade de que algo fosse feito também para os solicitantes. Foram então estabelecidas outras parcerias com ONGs para que cursos técnicos fossem oferecidos a eles. Através da parceria Casp/Sesc-Carmo também é oferecido um curso de língua portuguesa de nível básico.

A questão da educação para os refugiados e solicitantes de refúgio, assim como a da documentação, está estreitamente vinculada à problemática do trabalho. De maneira geral, a integração dos refugiados gira muito em torno desse fator. A psicóloga do CAR destaca que fora essa via, a Casp não tem uma estrutura que de fato estimule um processo de integração.

Eles acabam não formando uma rede social. [...] Acho que tem uma preocupação, claro, que é a preocupação primária, de abrigar essas pessoas. De elas terem o que comer, o que vestir, mas não existem de fato projetos de integração dessas pessoas na sociedade, a não ser pela via do trabalho. Mas até que isso aconteça, o que acaba levando alguns meses, as pessoas ficam meio à deriva.

Como me colocou a assistente social responsável pelo programa de integração, o solicitante de refúgio já pode começar o processo de integração quando já está com a documentação em dia. O refugiado que já pode ser integrado é aquele que enfim já é compreendido como um sujeito de direitos, que poderá ser um cidadão pleno, e que é visível, portanto, ao olho do Estado. O processo de integração também vai tratar de mantê-lo assim, gerindo o que escapa a esse mecanismo de governo, seus pontos $\operatorname{cegos}^{8}$ - o "se virar",

8 A noção de ponto cego, no contexto específico deste trabalho, refere-se às dimensões do real (Scott, 1998) que não são legíveis ao mecanismo de governo descrito, por não poderem ser mapeadas e estabilizadas por ele. Aproxima-se da noção de "limbo" mobilizada pelos funcionários do CAR para se referirem às relações que não são apreendidas pelo aparato burocrático e assistencial que operam, uma vez que não se encaixam nas categorias e normas particulares que este produz. Nesse caso, portanto, não se trata da mesma mobilização da noção de ponto cego feita por Vianna (2010, p. 32), que a compreende como a forma pela qual "a relação oficial entre organizações revela-se, no exame etnográfico, o efeito de alianças firmadas entre seus fragmentos, que se engancham a emaranhados institucionais de alcance em geral muito mais longo do que aquela simples relação pode levar a crer”. No contexto desta pesquisa, porém, a noção de ponto cego descrita por Vianna pode ser percebida no modo como "Brasília" se apresenta distante e ilegível para os solicitantes de refúgio, que só acessam diretamente dimensões do trabalho cotidiano realizado no CAR. A organização Conare fica assim eclipsada pelo CAR, constituindo seu ponto cego nesse trecho do emaranhado institucional de longo alcance a que se conecta.

Horizontes Antropológicos, Porto Alegre, ano 20, n. 41, p. 303-330, jan./jun. 2014 
o trabalho informal, a rua, a deriva, a ilegalidade - através de mecanismos como a "conscientização", a formação de uma "rede social”, e a "solidarização" e "sensibilização" da população local.

A busca por recuperar os direitos e a dignidade que teriam sido perdidos por esses sujeitos é o etos que informa o processo de constituição dos refugiados e dos solicitantes de refúgio como sujeitos de direito plenos, pela dimensão assistencial-humanitária apresentada. Este sujeito pleno é aquele que tem um local de moradia, condições adequadas de alimentação, formação educacional garantida, que trabalha formalmente e que, portanto, tem seus direitos trabalhistas assegurados. Tal processo de subjetivação terminaria com a integração na sociedade local, conformando o sujeito plenamente visível para o olho do Estado.

\section{Efeitos de Estado do mecanismo e governo}

A produção do sujeito de direito visível e que possa vir a ser um cidadão pleno é um dos efeitos de Estado produzido pelo trabalho da Casp, enquanto um dispositivo de governo. Mais que delimitar uma entidade Estado como uma realidade institucional autocontida, tais efeitos de Estado destacam as táticas e efeitos de poder que operam através de toda formação social, produzindo as fronteiras dos territórios e dos modos como cada coisa deve ser governada, através dos encontros e negociações das pessoas com as práticas burocráticas e assistenciais. "A linha entre domínios do Estado e não Estado é parcialmente desenhada pelas práticas de trabalho cotidianas de burocratas e em seus encontros.” (Mitchell, 2006, p. 16, tradução minha).

Essa forma de operar pode ser percebida, por exemplo, através das categorias de "limbo" e "sistema” usadas pelos funcionários. Sendo "limbo" o que escapa ao olho do Estado, ou o que ele vê parcialmente, precisando ser gerido - trazido de volta à curva de normalidade estabelecida pelo aparato. Refere-se principalmente ao que só se acessa via burocracia. Já o "sistema” é o campo de visibilidade mais legível para o olho do Estado, ou o que ele acessa através da burocracia. Os relatórios de prestação de contas dos auxílios recebidos pela instituição, por exemplo, são uma forma de tornar legível a esfera assistencial do trabalho, colocando-a na escala do "sistema" burocratizado.

Nesse aparato toda a rede de relações entre a Casp e as agências com as quais ela se conecta são ativadas por papéis, ligações, e-mails, cargos, projetos, formulários, convênios, encaminhamentos, pastas, fichas, valores, 
moralidades, códigos de ética, vontades, etc., que contribuem para a produção do sujeito visível ao olho do Estado, enquanto um sujeito de direito, que pode vir a ser um cidadão pleno e integrado.

Mas como esse sujeito pode permanecer visível, se, como foi apontado, o aparato burocrático-administrativo que o torna legível, mesmo com a dimensão assistencial-humanitária operando, possui ainda o que chamei de pontos cegos, isto é, dimensões da "prática", que esse mecanismo de governo não consegue acessar? É nesse momento que o processo de integração vai adquirir características de um dispositivo de gestão diferencial. Para manter os sujeitos visíveis e legíveis ao "sistema", para que não fiquem no "limbo", os atendimentos no setor de Integração trabalharão para mantê-los próximo da curva de normalidade determinada para caracterizar o sujeito de direito pleno e visível que o aparato descrito busca produzir.

Portanto, o sujeito passível de integração e, no limite, de gestão, já passou por duas etapas. Primeiramente passou pelo cadastro burocrático, tornando-se um sujeito inteligível ao olho do Estado. Em segundo lugar, passou pela produção do sujeito de direito pleno, visível como alvo da intervenção de um mecanismo de governo. Com o fim do processo de integração - entendido como um processo de recuperação de diretos perdidos - uma gestão diferencial dos casos particulares buscará evitar que estes se afastem das codificações visíveis ao olho do Estado, gerindo seus pontos cegos.

O trabalho de integração vai criar novos vínculos para esse sujeito em conformidade com a curva de normalidade estabelecida pelo aparato - o sujeito de direito pleno. Ele deve ser integrado como trabalhador, como alguém que tem moradia, alimentação, acesso à saúde e educação, e também como uma pessoa documentada. Ao final desse processo, é o laço da cidadania que lhe poderá ser conferido.

\section{Considerações finais}

A proposta deste trabalho foi a de compreender como opera um mecanismo através do qual determinados sujeitos se tornam visíveis a um aparato institucional, de modo que sobre eles se possa exercer um determinado tipo de intervenção - um governo -, seja assistencial, burocrático, humanitário, administrativo ou de controle. Para tanto, procurei tratar de um processo de subjetivação singular: aquele que compõe a categoria refugiado no contexto institucional brasileiro. 
A cada nova documentação que adquire e a cada novo cadastro em um programa assistencial, esse sujeito refugiado torna-se visível ao olho do Estado, assim como são produzidos os efeitos de Estado através dos quais esse aparato transnacional de gestão, territorializado no trabalho do CAR, cria uma população governável: cujas condutas poderão ser dirigidas ao serem estabilizadas suas complexidades em processos de categorização e padronização.

Visíveis como problema internacional e codificados a partir de uma definição jurídica, esses sujeitos podem ser compreendidos como uma população sobre a qual é possível realizar determinada intervenção. É constituído, então, todo um aparato institucional encarregado de gerir suas condições de vida, composto por organizações que vão de agências multilaterais internacionais a aparelhos estatais e organizações locais da sociedade civil - conformando-se um aparato trasnacional de governo. O que procurei destacar neste trabalho, a partir do enfoque dado aos atendimentos realizados no CAR, é que essas organizações não atuam de forma verticalizada e hierárquica apenas, mas através de conexões nas quais são conformados compósitos de relações. Tais composições podem ser observadas, por exemplo, nas parcerias entre organizações da sociedade civil, nos convênios entre o Acnur e governos nacionais, ou nos acordos de cooperação entre diferentes países.

O trabalho realizado no CAR produz um sujeito refugiado constituído como um compósito específico de inúmeras relações de poder, que o atravessam quando em contato com o dispositivo burocrático-administrativo e assistencial-humanitário etnografado. Documentado e assistido, o refugiado torna-se uma categoria legível e visível ao olho do Estado, que pode então tecer um mapa que estabilize a complexidade dessa população e permita codificá-la em sua particularidade em meio à população nacional. O "campo de refugiados sem cercas” conformado por esse aparato transnacional de gestão, quando visto em seu modo de funcionamento - a estabilização e codificação das complexidades de uma população em categorias visíveis e legíveis ao olho do Estado - pode ser compreendida como um modo de operação não apenas das state-like institutions, as organizações paraestatais abordadas neste artigo, mas do aparato estatal de modo geral.

Mais do que esperar encontrar a definição que fixaria a fronteira entre as organizações envolvidas nessa problemática, ou entre níveis locais, nacionais e globais de atuação dessas agências, como se este fosse um procedimento preliminar para a demonstração de como uma dimensão é dependente ou 
autônoma em relação à outra, procurei, portanto, examinar os processos sempre políticos pelos quais a incerta, mas poderosa distinção entre Estado, sociedade e comunidade internacional é criada (Ferguson, 2006). Desse modo tomo essa distinção entre as dimensões organizacionais de operação desse aparato, não como a fronteira entre entidades distintas e autocontidas, mas como uma linha desenhada internamente, em uma rede de mecanismos institucionais pelos quais uma ordem social e política é mantida (Mitchell, 2006).

Assim, o que este trabalho busca apresentar é um modo de funcionamento de organizações que produzem efeitos de Estado em suas práticas, através de um dispositivo de gestão que não apreende pessoas singulares, mas somente as categorias que ele mesmo estabelece. Dessa forma, tal mecanismo torna possível a estes gestores o exercício de uma intervenção sobre determinadas categorias de pessoas, modulando suas especificidades e produzindo um governo de suas condutas.

\section{Referências}

FERGUSON, J. Transnational topographies of power. In: FERGUSON, J. Global shadows: Africa in the neoliberal world order. Durham: Duke University Press, 2006. p. 89-122.

FOUCAULT, M. Segurança, território e população. São Paulo: Martins Fontes, 2008.

JUBILUT, L. L. A acolhida da população refugiada em São Paulo. In: RODRIGUES, V.; DA SILVA, C. A. S. (Org.). Refugiados. Vila Velha: Nuares, 2005. p. 95-129.

LEÃO, R. Z. R. A temática do refúgio no Brasil após a criação do Comitê Nacional para os Refugiados - CONARE. In: MILESI, R. (Org.). Refugiados: realidade e perspectivas. Brasília: CSEM/IMDH; Loyola, 2003. p. 173-196.

MITCHELL, T. Society, economy, and the State effect. In: SHARMA, A.; GUPTA, A. The Anthropology of State: a reader. Oxford: Blackwell Publishing, 2006. p. 169-186. 
MOREIRA, J. B. A questão dos refugiados no contexto internacional (de 1943 aos dias atuais). Dissertação (Mestrado em Ciência Política)-Instituto de Filosofia e Ciências Humanas, Universidade de Campinas, Campinas, 2006.

SCOTT, J. Seeing like a State: how certain schemes to improve the human condition have failed. London: Yale University Press, 1998.

SHARMA, A.; GUPTA, A. The Anthropology of State: a reader. Oxford: Blackwell Publishing, 2006.

VARESE, L. Três elos da corrente dos direitos humanos. Caderno de Debates Refúgio, Migrações e Cidadania, n. 1, p. 7-12, 2006.

VIANNA, C. M. Os enleios da tarrafa: etnografia de uma parceria transnacional entre ONGs através de emaranhados institucionais de combate à pobreza. Tese (Doutorado em Antropologia Social)-Faculdade de Filosofia, Letras e Ciências Humanas, Universidade de São Paulo, São Paulo, 2010.

Recebido em: 31/08/2013

Aprovado em: 18/12/2013 